\title{
Fakes and fraud in commercial diets
}

\author{
Dan Larhammar
}

Department of Neuroscience, Unit of Pharmacology, Uppsala University, Uppsala, Sweden

Abstract

The interest in health-food products is intense among the general public and in the media. Many products are widely sold despite a lack of supporting scientific evidence. Several examples of fraudulent claims are given here, such as the non-existent compound said to be the active ingredient in the weight-reduction product called MicroMagic. Another example is Dr Peter J D'Adamo's blood group diet, which claims to be specifically designed for the different blood groups of the ABO system and to be able to alleviate symptoms of serious diseases. These products are marketed without support from scientific studies, and often contain totally unrealistic claims such as rapid and extensive weight loss without reduction in food intake. Sources are provided that contain critical evaluation of these types of exaggerated claims.

Keywords: ABO blood groups; blood group diet; weight-reduction diet

\section{Introduction}

The general public's interest in food, dieting and health seems unlimited. Advertisements and commercials continuously tempt and urge us to purchase food products, follow specific diets or take certain treatments claimed to be beneficial for our health (1). Among the many diets and products for promotion of health, the most cynical are probably those that claim to achieve weight reduction. With promises about rapid weight loss, many desperate and disillusioned people are lured into testing useless products. Other diets and food supplements are claimed to ensure health and prevent diseases, particularly illnesses that appear late in life, meaning that many customers will be taking the remedy for years: prophylactic products constitute a mouthwatering business concept for manufacturers.

The health sections in the tabloid press and newspapers frequently propagate these products and concepts. In contrast, well-designed scientific studies of the claimed effects rarely if ever reach the tabloid health sections. One reason for this is probably that very few products have been tested with scientific methods. Another reason may be that tests come out negative, i.e. no convincing effects can be demonstrated, and such results are notoriously difficult to publish in scientific journals as well as in news media. A reason why so few of the commercial diets have been investigated is probably that the manufacturers do not even try to perform costly clinical trials that fulfil scientific criteria because they are aware that the effects are likely to be negligible. Stringent tests of diets may be difficult to carry out, but the absence of wellsupported effects does not seem to deter manufacturers from making far-reaching claims of effects in their marketing of the diets.

\section{Fraudulent weight-reduction products}

The list of dieting products that are sold with unsupported or irrational claims is very long. Only the most unrealistic claims lead to action by federal authorities such as the Swedish National Food Administration (Livsmedelsverket) or the Swedish Medical Products Agency (Läkemedelsverket). A few examples will be mentioned here. One is the dieting product sold under the name MicroMagic during 1999-2001, marketed by a company called Body and Soul. Its miraculous effects on body weight were ascribed to an ingredient called in Swedish "krom aminosyraklat", which was said to change the body's energy consumption so that energy would be retrieved from fat instead of water and thereby lead to weight loss. Anybody who says that water is an energy source either is completely illiterate regarding metabolism or is a bold liar. The named ingredient does not exist. The product disappeared after its claims were criticized in newspapers and in a consumers' programme on television.

Another fake product a few years ago was $\mathrm{Pu}-\mathrm{Erh}$, tea capsules marketed by a company called 
Swisstrade, based in Copenhagen. The order form asked the customer to tick the desired extent of weight loss: 5-9 kg (normal diet), 9-16 kg (super diet) or $16-25 \mathrm{~kg}$ (superintense diet). The more extensive diets were more expensive. The advertisement included a weight-loss diagram which at first glance may have given an impression of scientific credibility, but no scientific trials have been reported in peer-reviewed journals. Swisstrade was marketing no fewer than seven distinct weight-loss products with similar exaggerated claims such as "Eat what you want - and still lose weight" and "slim in no time". The company's marketing was prohibited by the Swedish Consumer Agency (Konsumentverket) in 2002.

A regimen called "Homoeopath Sorensen's recipe with SyB 62i" was sold by a firm called Nordiska Naturhuset AB during 2002. The advertisement purported that one client had lost $52 \mathrm{~kg}$ simply by taking the pills before every meal. No documentation was provided to support this claim. The product was prohibited by the Consumer Agency in 2003. During 2003 and 2004, a company called Health Mail, based in Malmö, marketed two products called the Hollywood Diet and Algolean. As above, the customer could simply tick the desired extent of weight loss and pay accordingly. No clinical studies have been published that support the claims in the advertisements, let alone the doseresponse relationship.

A weight-loss product that had some support for its claims was Eat \& Lose, imported and marketed during 2002 by a company in Norrköping called MaxiElit. The reason why weight loss may have been achieved by some customers was that the herbal extract contained potent components such as thyroid hormone $\left(\mathrm{T}_{3}\right)$ and ephedrine. However, these compounds give rise to heart fibrillation and tachycardia (increased heart rate) even at very low doses. Ephedrine is thought to have caused several deaths. After a number of reports to the Consumer Agency, the product was removed from the market. The dose of $T_{3}$ in each capsule was far higher than the initial dose used in clinical treatment of reduced thyroid function.

\section{The blood group diet}

The so-called blood group diet has been marketed widely by the American naturopath Peter $\mathbf{J}$ D'Adamo. His book "Eat right for your type" (1996) has sold over two million copies and has been translated to more than 50 languages, including Swedish in 2002 with the title "Ät rätt för din blodgrupp". Its basic idea is that one should adhere to one of a few specific diets that are claimed to have been specifically designed for the blood groups of the ABO system. The diets purportedly prevent or cure various diseases. The author is described as a naturopathic doctor and researcher, but neither he nor anybody else has published scientific studies that support his claims.

The blood group diet concept is based on two principles. The first is that lectins in food cause health problems by binding to the blood group antigens of the $\mathrm{ABO}$ system. (Lectins are proteins that bind to carbohydrate structures.) D'Adamo claims that lectins in chicken can lead to agglutination of blood cells and thereby cause stroke and immune deficiency in humans with blood group B. $\mathrm{He}$ even claims that lectins can aggregate in the kidneys and cause death. No scientific investigations are presented that support these extraordinary claims. In fact, lectins are present on all cell surfaces in foodstuffs as well as in our own bodies. There are no reports that lectins in food would be taken up from the gastrointestinal tract and cause problems unique to individuals with certain blood groups.

The second concept of the blood group diet is that the blood groups, particularly A and B, arose quite recently in human evolution in conjunction with a change in eating habits. D'Adamo claims that blood group $\mathrm{O}$ is the most ancient. However, the situation is in fact the opposite: the gene variants that give rise to blood groups $\mathrm{A}$ and $\mathrm{B}$ are the oldest, whereas $\mathrm{O}$ is a non-functional gene variant that arose through a more recent mutation. More specifically, individuals with blood group $\mathrm{O}$ have lost the ability to synthesize the carbohydrate groups on the body's cells that the enzyme variants $\mathrm{A}$ and $\mathrm{B}$ can make. The literature references in D'Adamo's book to studies of blood group anthropology and evolution are quite old and do not include the molecular genetic results that have been reported during the past several years.

The most remarkable aspect of D'Adamo's book is probably the brief case histories that give the reader the impression that the ABO diets can be used to treat deadly diseases such as AIDS and cancer. D'Adamo describes a patient with fully developed AIDS who was advised to exclude all types of poultry (except for turkey) and several other energy-rich foods from his diet. Three months 
later the patient's condition had improved, according to D'Adamo. An HIV-positive woman who had followed diet $\mathrm{O}$ was reported to have returned to normal blood values and to have become free of symptoms. Another women, after surgery for breast cancer, who had developed lymphoid metastases, was prescribed a "cancer diet" in accordance with blood group $\mathrm{AB}$ and was reported to have lowered her level of a tumour marker. These and additional remarkable case histories are included in the American issue of the book printed in 1996 and in the Swedish translation in 2002. The case histories should have been complemented with the current health status of the patients in the Swedish release.

If D'Adamo's efforts to treat these diseases had indeed worked, we would have learned about such sensational medical progress through the world's leading scientific journals. This has not happened: D'Adamo has not published a single scientific report about his "treatments" and remarkable hypotheses. Therefore, it is deeply irresponsible and unethical of D'Adamo and his Swedish publisher (Andersson Information \& Förlag $\mathrm{AB}$ in Karlstad) to continue to give readers the impression that these unfounded ideas about ABO-based diets would be able to cure or slow down deadly diseases. A thorough evaluation of the claims of the blood group diet have been published in the Swedish physicians' journal (2).

\section{Suggestions}

It is often difficult to find reliable and critical information about the pretentious products and regimens that are marketed by unscrupulous companies. Exaggerated claims can be hazardous, either if the products themselves cause harm or if the customer relies on the useless products instead of seeking evidence-based treatments. Therefore, professional medical experts and federal authorities must take more responsibility for evaluating and criticizing bombastic and incorrect claims.

Sadly, neither researchers nor authorities seem to have the necessary resources for such surveillance. This leaves the market open for self-proclaimed experts who may rapidly become famous media personalities and talk-show stars. This often is accompanied by best selling books which at best are full of platitudes, and may contain directly harmful advice. Critical reviews of this literature are as uncommon as scrutiny of the claims in healthfood advertisements. Fortunately, a few websites have assembled critical evaluations of the most exaggerated claims (3-7). This information will not only lead to increased awareness of the potential dangers with certain diets, but may also lead to an appreciation of the ridiculous aspects of the many ignorant and preposterous claims.

\section{References}

1. Isaksson H, Larhammar D. 2002 - skördeår för entreprenörer inom alternativmedicinen. Läkartidningen 2003; 100: 144-7.

2. Nylund K, Sjölin K, van der Ster G, Larhammar D. Blodgruppsdieten: fantasier och kvacksalveri. Läkartidningen 2004; 101: 3168-72.

3. Quackwatch: http://www.quackwatch.com/

4. National Council Against Health Fraud (NCAHF). http://www.ncahf.org/

5. Alternative medicine. http://www.discord.org/skeptical/ Alternative_Medicine/

6. http://www.bmc.uu.se/ danl/pseudovetenskap.html

7. http://www.bmc.uu.se/ danl/links.html

Dan Larhammar

Department of Neuroscience

Unit of Pharmacology

Uppsala University

Box 593

SE-75I24 Uppsala

Sweden

E-mail: Dan.Larhammar@neuro.uu.se 